\title{
Assessment of health promoting life styles among the under graduate students of Sri Venkateswara Institute of Medical Sciences (SVIMS) University, Tirupati, Andhra Pradesh
}

\author{
Sankar Deekala R. ${ }^{1}$, Sujith Kumar Dondapati S. ${ }^{2 *}$, Anju Damu A. ${ }^{3}$, Yamasani B. ${ }^{4}$, Vishnu Kandra
}

$\mathrm{N}^{5}{ }^{5}$, Mahammad Shareef $\mathrm{S}^{6}$

DOI: https://doi.org/10.17511/ijphr.2017.i5.02

\begin{abstract}
1 Ravi Sankar Deekala, Assistant Professor, ${ }^{2 *}$ Srinivasa Sujith Kumar Dondapati, Associate Professor, ${ }^{3}$ Ade Anju Damu, Professor, 4 3Bhavani Yamasani, Assistant Professor, ${ }^{\mathbf{5}}$ Naga Vishnu Kandra, Tutor, ${ }^{6}$ Suleman Mahammad Shareef, Public Health Nurse; all authors are affiliated with Department of Community Medicine, Sri Padmavathi Medical College for Women, Tirupati, Andhra Pradesh, India.
\end{abstract}

Background: Health promoting behaviours, including self-initiated actions, behaviours, and health perceptions may have an impact on individual happiness and well-being. Objectives: To study health promoting life style among the first year under graduate students of Sri Venkateswara Institute of Medical Sciences University and compare the health promoting life style profiles between the first year under graduate students of different courses of the University. Methods: A Selfadministered Questionnaire containing Health Promoting Life Style Profile - II questionnaire developed by Walker et al. was distributed to the students and were asked to answer all the questions and return the same. Results: A total of 354 students participated in the study. Of these students $42 \%, 28 \%, 16 \%$ and $14 \%$ were pursuing MBBS, Bachelor of Physiotherapy, BSc Nursing and BSc Paramedical courses respectively. Students had highest score in Interpersonal relations (2.98 \pm 0.45), Spiritual growth (2.91 \pm 0.45$)$ and Stress management (2.63 \pm 0.43$)$. Lowest scores in Physical activity (2.08 \pm 0.6$)$, Health Responsibility $(2.18 \pm 0.5)$ and Nutrition $(2.4 \pm 0.44)$. Conclusion: There was no significant difference between specialities in terms of HPLP scale scores and all subscale scores.

Keywords: HPLP-II, Students, Specialities

\section{Corresponding Author}

Srinivasa Sujith Kumar Dondapati, Associate Professor, Department of Community Medicine, Sri Padmavathi Medical College for Women, Tirupati, Andhra Pradesh, India.

Email: doctorsujith@gmail.com

\section{How to Cite this Article}

Deekala RS, Dondapati SK, Damu AA, Yamasani B, Kandra NV, Shareef SM. Assessment of health promoting life styles among the under graduate students of Sri Venkateswara Institute of Medical Sciences (SVIMS) University, Tirupati, Andhra Pradesh. Public Health Rev Int J Public Health Res. 2017;4(5):112-116.

Available From

https://publichealth.medresearch.in/index.php/ijphr/ article/view/70
To Browse

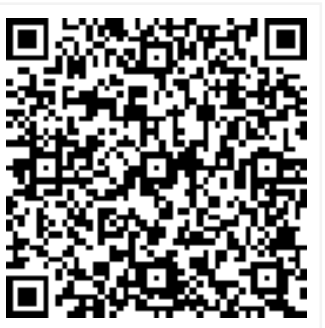

Manuscript Received 2017-11-24

Conflict of Interest No
Review Round 1 2017-12-01

Funding

Nil

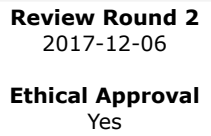

Ethical Approval Yes

Review Round 3

Plagiarism X-checker $5 \%$
Accepted 2017-11-14

Note

(c) 2017 by Ravi Sankar Deekala, Srinivasa Sujith Kumar Dondapati, Ade Anju Damu, Bhavani Yamasani, Naga Vishnu Kandra, Suleman Mahammad Shareef and Published by Siddharth Health Research and Social Welfare Society. This is an Open Access article licensed under a Creative Commons Attribution 4.0 International License https://creativecommons.org/licenses/by/4.0/

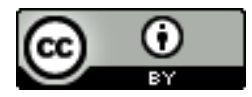




\section{Introduction}

Lifestyle is the way of living of individuals, families, and societies which can be healthy or unhealthy in terms of personal behaviours such as nutrition, physical activity, and stress management. A healthy lifestyle may result in better health and happiness, and in contrast, an unhealthy lifestyle may cause illness and morbidity [1].

Pender et al. indicated that health promoting behaviours (HPBs), including self-initiated actions, behaviours, and health perceptions may have an impact on individual happiness and well-being [2]. Healthcare students also suffer in term of Health and very little is being said about the empowerment of health to these students in their vigorous study timetable.

Health is taught but health promotion is not done. Health-promoting lifestyle should be promoted by setting example rather than delivering lecture [3]. The unhealthy life style and behaviour adopted during the college can have a sustaining impact on an individual's health latter in the life [4].

Hence promoting healthy lifestyle in students can have long term positive effect, since many of the behaviours and lifestyle habits are formed during this period. These young students can be moulded in better way to cope with their life by taking responsibility for their personal health [5]. Increasing evidence indicate that if individuals can practice properly and routinely, it would result in better health and lifestyle [6].

Sri Venkateswara Institute of Medical Sciences (SVIMS) university, Tirupati, Andhra Pradesh, India is conducting various courses of under graduate, post graduate and super speciality, in the field of health care sciences. The undergraduate courses include MBBS, Physiotherapy, Nursing and Paramedical sciences. Most of the under graduate students entering in to the university are in the age group of 17-21 years.

University students of this age group find it difficult to anticipate and cope with the sudden increase of professional studies on one hand and at the same time on other hand, physiological changes in the body that is in the process of making an impact in the body [7]. The number of studies on healthpromoting lifestyles among university students in Andhra Pradesh State are scarce.
The present study will examine the healthpromoting lifestyles of Undergraduate students of SVIMS University, Tirupati, which includes Medical, Physiotherapy, BSc Nursing and Paramedical courses with the help of Health Promoting Life Style Profile (HPLP-II) Questionnaire [5].

\section{Materials and Methods}

Place of study: SVIMS University, Tirupati, Andhra Pradesh

Type of study: Cross sectional analytical study

Sampling method: All first-year graduate students of SVIMS university who are present and willing to participate voluntarily on the day of data collection.

Sample collection: Self-administered pretested questionnaire

Inclusion Criteria: First Year under graduate students of SVIMS university, including MBBS, BSC Nursing, BPT, BSc Paramedical students who are present and willing to participate voluntarily on the day of data collection

Exclusion criteria: Those students not willing to participate and students absent on the day of data collection.

Statistical methods: Data was analysed by using Epi Info $^{\mathrm{TM}}$ for windows Build 7.2.1, Release Date: 01/12/2017, Division of Health Informatics \& Surveillance (DHIS), Centre for Surveillance, Epidemiology \& Laboratory Services (CSELS). Descriptive statistics like Frequencies, means and standard deviations for the participant's characteristics and the HPLP - II scores were calculated. Analytical statistics like Chi square test or Fischer's exact tests were used for discrete data and ANOVA with post hoc analysis Test was used to examine the significant differences in the mean HPLP - II scores between various groups of participants and their characteristics. A p value of $<$ 0.05 and $<0.001$ was considered as significant and highly significant respectively.

Methodology: A Cross sectional analytical study was undertaken in 1st Year under graduate students of SVIMS university, Tirupati, Andhra Pradesh. 1st Year under graduate students of SVIMS university, including MBBS, BSC Nursing (BSC N), Bachelor of Physiotherapy (BPT), BSc Paramedical (BSC P) students who are present and willing to participate voluntarily on the day of data collection are included in the study. 
Those students not willing to participate and students absent on the day of data collection were excluded from the study.

Prior permission is obtained from the principals of the respected courses and written informed consent was taken from the students before starting the study. The participants were approached in their class rooms at stipulated time. Self-administered questionnaire was distributed to the students and were asked to answer all the questions and return the same.

The participants were given sufficient time to answer all the questions. The questionnaire has two sections. Section A contains participant's demographic details including name, age, course etc. Section B contains Health Promoting Life Style Profile (HPLP) - II questionnaire developed by Walker etal [5]. HPLP- II questionnaire contains 52 items and 6 subscales of health responsibility, physical activity, nutrition, spiritual growth, interpersonal relations and stress management.

Participants should respond to the Four point Likertlike-scale consisting of the options Never, Sometimes, Often and Routinely with scores 1, 2, 3 \& 4 respectively. The overall HPLP scores were calculated by taking mean of all 52 questions. To calculate the score for each of the six subscales, the mean of the responses to subscale items was calculated.

The mean scores of the scale was divided into 3 levels- Good (> 3); Average (2.5-3) and poor (< 2.5). These scores are used as an index of health promoting lifestyle, with a higher score indicating a higher level.

\section{Results}

Out of 360 1st year students 354 students participated in the study (Response Rate - 98.3\%). Majority of the participants were females 317 $(89.5 \%)$ followed by $37(10.5 \%)$ males. Minimum and maximum ages of the participants was 17 and 23 years respectively with mean age of 18.4 years.

There are no males in MBBS course as it is women's medical college. Of these students $42 \%, 28 \%, 16 \%$ and $14 \%$ were pursuing MBBS, Bachelor of Physiotherapy (BPT), BSc Nursing and BSC Paramedical courses respectively. $92 \%$ of the students belonged to Hindu religion. $80 \%$ of the children were from nuclear families and living away from their families (Hostel).
$39 \%$ of students belong to Upper middle class, $25 \%$ belong to Upper class and $24.6 \%$ belong to Lower middle class of Modified Kuppuswamy Socio economic status scale of 2016.

Table-1: specialty wise age distribution of study subjects

\begin{tabular}{|l|l|l|}
\hline \multirow{2}{*}{ Speciality } & \multicolumn{2}{c|}{ Sex } \\
\cline { 2 - 3 } & Female (mean age) & Male (mean age) \\
\hline Bachelor of Physiotherapy & 18 & 18 \\
\hline BSc Nursing & 18 & 19 \\
\hline BSc Paramedical & 18 & 18 \\
\hline MBBS & 19 & NA \\
\hline
\end{tabular}

Present study revealed HPLP II mean score of 2.54 \pm 0.33 among the 1 st year under graduate students of SVIMS University. Students had highest score in Interpersonal relations $(2.98 \pm 0.45)$, Spiritual growth (2.91 \pm 0.45$)$ and Stress management (2.63 \pm 0.43 ). Lowest scores in Physical activity (2.08 \pm $0.6)$, Health Responsibility (2.18 \pm 0.5$)$ and Nutrition (2.4 \pm 0.44 ). Overall Good (mean score $>$ 3) HPLP II score was seen in $7.6 \%$ (27).

Average (mean score 2.5-3) HPLP II was seen in $46 \%$ (163). Poor (mean score < 2.5) HPLP II score was seen in $46.3 \%$ (164). BSc Paramedical students had high percentage of Good score (12.2\%) followed by BPT (8.3\%), BSc Nursing (8\%) and MBBS (5.3\%). BSc Nursing students had high percentage of Average score (58\%) followed by MBBS (44.9\%), BPT (39.5\%) and BSc Paramedical (35\%).

BSc Paramedical students had high percentage of Poor score (52.6\%) followed by BPT (52\%), MBBS (49.6\%) and BSc Nursing (34\%). There was no overall significant difference between Specialities in HPLP scores and all subscales scores $(p>0.05)$. There was significant difference among the mean scores between the groups of Specialities regarding HPLP $(p=0.035)$, Health Responsibility $(p<0.01)$ and Physical activity $(p<0.01)$.

The difference was not significant regarding remaining sub-scales $(p>0.05)$. ANOVA with Post hoc Analysis revealed Significant difference between BSc Nursing and MBBS regarding mean HPLP scores $(p=0.026)$. Significant difference between BSc Nursing and MBBS $(p<0.001)$, BSc Nursing and BPT $(p=0.029)$. Regarding mean Health responsibility sub scale and Significant difference between BPT and MBBS $(p=0.025)$, BSc Nursing and MBBS $(p<0.001)$ regarding physical activity subscales. 
No Significant difference was noted between the groups regarding mean score of remaining subscales $(p>0.05)$. Gender wise significant difference was noted between the mean scores of Physical activity subscale only $(p<0.001)$.

\section{Table-2: Speciality wise differences in HPLP sub-scales}

\begin{tabular}{|l|l|l|l|c|c|}
\hline \multicolumn{1}{|c|}{ HPLP Sub-Scales } & Sum of Squares & df & Mean Square & F & Sig. \\
\hline Health Promoting Lifestyle & .933 & 3 & .311 & 2.893 & .035 \\
\hline Health Responsibility & 5.586 & 3 & 1.862 & 7.742 & .000 \\
\hline Physical Activity & 7.489 & 3 & 2.496 & 7.079 & .000 \\
\hline Nutrition & 1.496 & 3 & .499 & 2.595 & .052 \\
\hline Spiritual Growth & .561 & 3 & .187 & .901 & .441 \\
\hline Interpersonal Relations & .485 & 3 & .162 & .762 & .516 \\
\hline Stress Management & 1.403 & 3 & .468 & 2.470 & .062 \\
\hline
\end{tabular}

Mean HPL score is 2.54 with $46.3 \%, 7.6 \%$ and $46 \%$ belonging to average, good and poor groups respectively. Mean Health Responsibility score is 2.18 with $18.4 \%, 6.2 \%$ and $75.4 \%$ belonging to average, good and poor groups respectively.

Mean Physical Activity score is 2.08 with $18.6 \%$, $7.1 \% \%$ and $74.3 \%$ belonging to average, good and poor groups respectively. Mean Nutrition score is 2.40 with $33.6 \%, 7.9 \% \%$ and $58.8 \%$ belonging to average, good and poor groups respectively.

Mean spiritual growth score is 2.91 with $44.4 \%$, $37.6 \% \%$ and $18.1 \%$ belonging to average, good and poor groups respectively. Mean Interpersonal Relations score is 2.18 with $42.7 \%, 42.1 \% \%$ and $15.3 \%$ belonging to average, good and poor groups respectively.

Mean Stress Management score is 2.63 with $52.5 \%$, $15.3 \% \%$ and $32.2 \%$ belonging to average, good and poor groups respectively.

Table-3: Post-hoc analysis of inter speciality differences in HPLP sub-scales

\begin{tabular}{|l|l|l|l|}
\hline \multicolumn{1}{|c|}{ Scale } & Difference in Mean & P value & \multicolumn{1}{c|}{ Group } \\
\hline HPLP II Score & 0.11529 & 0.026 & BSC N and MBBS \\
\hline Health responsibility & -0.29881 & $<0.001$ & BSc N and MBBS \\
\cline { 2 - 5 } & -0.24630 & 0.029 & BSC N and BPT \\
\hline Physical activity & -0.28997 & 0.025 & BPT and MBBS \\
\cline { 2 - 5 } & -0.32883 & $<0.001$ & BSc N and MBBS \\
\hline Nutrition & NIL & $>0.05$ & \\
\hline Spiritual growth & NIL & $>0.05$ & \\
\hline Interpersonal relations & NIL & $>0.05$ & \\
\hline Stress management & NIL & $>0.05$ & \\
\hline
\end{tabular}

\section{Discussion}

The aim of this study was to evaluate the health promoting lifestyle behaviours among under first year graduate students in the beginning of their career so as to find effective intervention measures related to their health status. The HPLP-II score reflect the student's commitment of health maintaining act, so better is the score, better will be the health profile of a student.

Study participants belong to 17-23 years' age group with mean of 18.4 years which is similar to study done by Sunil Chouhan in Madhya Pradesh [8]. Overall mean HPLP II score of present study was $2.54 \pm 0.33$, which is similar in the study conducted by Melis Naçar et al in Turkey [9], where as low mean score was found in a study done in Madhya Pradesh [8].

Similar moderate result were seen in some other studies $[10,11]$. Males have high HPLP mean score compared to Females in the present study (2.6 \pm 0.6 Vs $2.53 \pm 0.32$ ). Similar results came in a study done by Sunil Chouhan in Madhya Pradesh [8].

The highest score on interpersonal relations of the present study $(2.98 \pm 0.45)$ and lowest score of physical activity among the female was similar in a study done by Ali Mehri et al among University Students in Sabzevar, Iran [12]. The lowest score among female was on physical activity $2.03 \pm 0.59$.

Similar results came in a study done by Suraj Senjam \& Amarjeet Singh among college students in Chandigarh, India [13]. Poor health Responsibility among the male students was similar with a study done in India [8]. High spiritual growth scores among both sexes were corresponding to the study done in Madhya Pradesh [8]. Low nutritional status score and physical activity among the female gender is similar with a study done by Ali Mehri et al [12].

\section{Author contributions}

01. Dr Ravi Sankar Deekala: Study designing, protocol preparation, Institutional Ethics Committee approval, Data collection , Data entry, Data analysis \& manuscript preparation.

02. Dr Srinivasa Sujith Kumar Dondapati: Study designing, protocol preparation, Data analysis \& manuscript preparation.

03. Dr Anju Damu Ade: Protocol and manuscript preparation. 
04. Dr Bhavani Yamasani: Protocol and manuscript preparation.

05. Dr Naga Vishnu Kandra: Data collection, Data entry.

06. Mr Suleman Mahammad Shareef: Data collection.

\section{Conclusion}

A total of 354 students participated in the study. Majority of the participants were females pursuing MBBS, Hindus, from nuclear families, living away from their homes in hostels belonging to Upper middle-class families. Mean scores for HPLP II, spiritual Growth, Interpersonal relations and Stress Management were in the average range while mean scores for Health responsibility, Physical activity and Nutrition were in the poor status. There was no overall significant difference between Specialities in HPLP scores and all subscales scores.

There was significant difference among the mean scores between the groups of Specialities regarding HPLP, Health Responsibility and Physical activity. The difference was not significant regarding remaining sub-scales. Significant difference exists between BSC Nursing and MBBS regarding mean HPLP scores. Significant difference exists between BSc Nursing and MBBS, BSc Nursing and BPT regarding mean Health responsibility sub scale. Significant difference exists between BPT and MBBS, BSc Nursing and MBBS in physical activity subscales.

\section{Usefulness of this study}

This is the first study done in India among the medical and Allied health science students of medical university. This study found that health responsibility and physical activity is better among allied health science students compared to medical students.

\section{Reference}

01. Saffari $M$, Amini $N$, Eftekhar Ardebili $H$, Sanaeinasab $H$, Mahmoudi $M$, Piper CN. Educational intervention on health related lifestyle changes among Iranian adolescents. Iran J Public Health. 2013;42(2)172-81.

[Crossref]

02. Pender NJ, Muraugh CL, Parsons MA. Health Promotion in Nursing Practice. 4thed, New Jersey: Prentice Hall PTR. 2005.

[Crossref]
03. Whitehead D. Health promotion and health education- advancing the concepts. J Adv Nurs. 2004;47(3)311-20.

[Crossref]

04. Lee RL, Loke AJ. Health-promoting behaviors and psychosocial well-being of university students in Hong Kong. Public Health Nurs. 2005;22(3)209-20.

[Crossref]

05. Walker SN, Sechrist KR, Pender NJ. The HealthPromoting Lifestyle Profile- development and psychometric characteristics. Nurs Res. 1987;36(2)76-81.

[Crossref]

06. Pender NJ, Murdaugh CL, Parsons MA. Health $\mathrm{Pr}$ omotion in Nursing Pra ctice. 6th ed, USAPearson. 2010.

[Crossref]

07. World Health Organization. Coming of age- from facts to action for adolescent sexual and reproductive health. Geneva- WHO. 1977.

[Crossref]

08. Chouhan S. Analysing health promoting life styles of medical students in Bhopal, Madhya Pradesh, India by HPLP-II. Int J Community Med Public Health. 2017;4(1)195-9.

DOI: [Article] [Crossref]

09. Mahdipour N, Shahnazi H, Hassanzadeh A, et al. Relationship between various aspects of life style in middle-aged women. Bull Environ Pharmacol Life Sci. 2013;3(1)68-74.

[Crossref]

10. Jian FH, Santhat S, Boonyong K. Health prom oting lifestyles of nursing students in Mahidol university. J Public Health Dev. 2007;5(1)27-40. [Crossref]

11. Melis Naçar et al. Health Promoting Lifestyle Behaviour in Medical Students- a Multicentre Study from Turkey. Asian Pac J Cancer Prev. 2014;15(20)8969-74.

DOI: [Article] [Crossref]

12. Ali Mehri, et al. Health Promoting Lifestyle and its Determinants Among University Students in Sabzevar, Iran. Int J Prev Med. 2016;14(7)65. doi: $10.4103 / 2008-7802.180411$ [Crossref]

13. Senjam S, Singh A. Health promoting behaviour among college students in Chandigarh, India. Ind J Comm Heal. 2012;24(1)58-62.

[Crossref] 